\title{
Global Scrap Trading Outlook Analysis for Steel Sustainability
}

\author{
H. Lee $\cdot$ I. Sohn
}

Published online: 30 January 2015

(C) The Minerals, Metals \& Materials Society (TMS) 2015

\begin{abstract}
Using the global scrap commodity trading data during the period between 1990 and 2013, the steel scrap network relationship between countries has been ascertained. By connecting the various steel scrap trading countries and forming relationship sub-groups, the scrap centrality of trading countries was identified from the Katz status index. Developed countries such as the USA and Germany had a high centrality for exporting steel scrap in the network, and Turkey and Korea had a high centrality for importing steel scrap in the network. The steel scrap utilization correlated well with the steel production according to Pearson's model. Steel scrap forecasting based on the time-series analysis estimates scrap demand in 2018 to be approximately 750 MT with approximate steel production exceeding $1.75 \mathrm{BT}$. The forecasted steel scrap supply is likely to be sufficient for the steel industry, but centrality of some countries such as the Russian Federation and UK is lower than expected, and there may be some opportunities for these countries to expand its trade network for increased flexibility and utilization of scrap for higher steel sustainability.
\end{abstract}

Keywords Scrap $\cdot$ Import $\cdot$ Export $\cdot$ Centrality $\cdot$ Steel forecast

\footnotetext{
H. Lee

Yonsei Institute of Green Technology, Yonsei University, Seoul 120-749, Korea

I. Sohn $(\bowtie)$

Materials Science and Engineering, Yonsei University,

Seoul 120-749, Korea

e-mail: ilsohn@yonsei.ac.kr
}

\section{Introduction}

Steel is known to be the most recycled material in the anthropogenic ecosphere standing at $88 \%$ in 2012 according to the American Iron and Steel Institute [1]. Recycled steel, commonly referred to as 'steel scrap,' can be in many forms and is derived from vehicles to construction and consumer appliances. Steel within vehicles has a recycling rate of over $92 \%$, and from appliances has a recycling rate of over $90 \%$. The high scrap utilization back into the steel shop for re-use and recycling in steel production increases the environmental sustainability of the material.

In the recycling of steels, the quality and logistics determine the cost of the scrap and eventual economic viability of scrap usage. While the EAF (electric arc furnace) feed material uses mostly scrap and scrap substitutes such as DRI (direct reduced iron) or HBI (hot briquetted iron), the BOF feed material uses mostly hot metal saturated in carbon and approximately $20 \%$ scrap [2]. Countries with excess hot metal such as China have utilized significant amounts of hot metal in both the EAF and BOF, which decreases the percentage of scrap utilization, but considering the sheer volume of Chinese steel production China is still a large consumer of steel scrap.

Recent materials cost for iron ore in the second quarter of 2014, which is the feed for the integrated steel mill including the BOF, show a drop to below $90 \mathrm{USD} /$ ton from its average of $140 \mathrm{USD} / \mathrm{ton}$ in 2013. However, No. $1 \mathrm{HSM}$ (heavy melting steel) scrap traded at $350 \mathrm{USD} /$ ton has not significantly changed from its average of $345 \mathrm{USD} / \mathrm{ton}$ in 2013. In addition, the EAF relies on electricity and costs have continued to rise in the past decade for many countries especially for Japan and Korea. Thus, a significant cost-advantage for the integrated steel mills exists, while 
the cost of iron ore raw materials is low. However, the EAF is perceived to be environmentally friendly compared to the integrated steel mills and as carbon taxes begin to be levied and expanded globally in the near future, there may be an additional environmental cost for the integrated steel mill that can make the EAF cost-effective in the long term if scrap availability is sufficient and scrap cost through logistics optimization is realized [3].

According to the Steel Recycling Institute, steel recycling of one ton in the steel industry can conserve about 1.1 ton of iron ore and 0.6 ton of coal yielding at least $75 \%$ savings in energy, and significant reduction in water and air pollution increasing the environmental sustainability of scrap utilizing steel processes [4]. Thus, understanding commodities trading of steel scrap in the global scale and diagnosing the network relationship of scrap trading, identifies the key players of scrap supply and demand, provides information on other potential candidates for scrap supply substitutes, and determines weaknesses in scrap trading, which can ultimately optimize the scrap utilization for greater steel sustainability.

Past studies on steel flow including scrap have utilized MFA (materials flow analysis) to estimate the scrap supply finding countries with a long industrial history such as the USA, UK, and Germany being close to the saturation value of in-use stocks to be approximately $13 \pm 2$ tons per capita [5]. Anthropogenic iron cycle using MFA found purchased scrap contributing to a quarter of the global iron and steel production, which focused on the iron stocks-in-use that can last for decades [6]. The quantitative estimates using MFA also utilize the production and trade statistics to estimate the apparent consumption of steel. Depending on the accuracy of the data, the precision of the analysis and estimates is limited, but can provide some insight to the forecast of steel flow [7]. However, while these studies provide detailed descriptions and attributes of the individual countries for scrap, the present study focuses on the network relationship between scrap trading countries and the possible grouping and centrality analysis. This centrality analysis can provide important information on the scrap supply and demand in the global trading scheme, and identify the dominant controllers of steel scrap supply at the present, as well as indicate the possible substantial scrap suppliers in the future.

In this study, the global scrap commodity trading data were obtained from the United Nations Commtrade database from the period between 1990 and 2013 and were used to identify the steel scrap network relationship between countries. The visual representation of the scrap trading network and centrality analysis has yet to be studied to the knowledge of the present authors. The import and export amounts of steel scrap trade were analyzed, and the scrap centrality of trading countries was identified from the Katz status index. Using the steel production data for individual countries from the World Steel Association, the steel scrap utilization and steel production were correlated using Pearson's model, and the outlook of the steel production and scrap demand to 2018 using the ARIMA model was shown. The identification of the network relationship and centrality analysis with an estimation of the short-term scrap forecast may provide optimization of steel scrap trading for the industry to allow sustainable development and supply of the scrap commodity in steel production.

\section{Methods and Procedure}

\section{Data Acquisition and Analysis}

The steel scrap commodity data were retrieved from the UN Commtrade during the period from 1990 to 2013. The data form was in year, amount of trade in tons, and trade value in USA dollars. The commodity HS (harmonized system) code number 7024 involves iron containing waste, scraps and scrap ingots for remelting steels. The detailed commodity codes for the present study and its list is shown in Table 1. It should be noted that there exists a gap between the imported and exported amount for identical HS codes of most countries. In other words, there is a discrepancy of the exported amount of an item by several countries to the target country and the imported amount by that target country. The direct cause of this discrepancy has yet to be fully understood, but most likely is due to issues relating to differences in the accounting for the amount of scrap by the importing and exporting countries, the incorrect data reporting to the Commtrade, and the time delay between the import and export of materials at different periods. An example of the time delay, if the scrap is

Table 17204 Ferrous waste and scrap, remelting scrap ingots of iron or steel commodity HS codes

\begin{tabular}{ll}
\hline $\begin{array}{l}\text { HS } \\
\text { code }\end{array}$ & Classification \\
\hline 72041 & Waste and scrap of cast iron \\
72042 & Waste and scrap of alloy steel \\
720421 & Of stainless steel \\
720429 & Other \\
72043 & Waste and scrap of tinned iron or steel \\
72044 & Other waste and scrap \\
720441 & Turnings, shavings, chips, milling waste, sawdust, filings, \\
720449 & Otrimmings, and stampings, whether or not in bundles \\
72045 & Remelting scrap ingots \\
\hline
\end{tabular}


shipped in October, it may take several months for the steel to be accounted for in the same fiscal year and thus will be included in the subsequent fiscal year. Thus, in this study, analysis on the import and export data was done separately to neglect the disparity of the equivalence of the import and export amount for an individual country. For data without net weight amount, the average price per commodity was used to estimate the traded amount. For countries that were unified or separated from past data within the time span of the present study, the current country name was utilized. For example, West and East Germany have been unified into Germany and Hong Kong and Macao have been unified into the China datasets.

It should be mentioned that within the ferrous scrap data taken for the analysis, non-ferrous elements can be contained as impurities. The authors have not modified the iron contents for each commodity since the compositional range of the ferrous scrap source was not available, which can increase the uncertainty of the calculation in the amount of iron source traded. Non-ferrous scrap items such as those for Al have HS codes starting with 7602.

\section{Forecast Model}

In time-series analysis, the time-series data are correlated to one another to estimate the forecasted value by considering the cause of change and the dynamic relationships involved. For the time-series analysis, the pre-limitation minimization model of the cause and effect relationship and the time difference distribution of the data are speculated. The amount of change at a particular time is affected by the past change amount and the past error (white noise). The application of this is the AR (auto regressive) model. Assuming a fixed error value, which is not infinite, the MA (moving average) model is applied. The combination of the AR and MA models is termed the ARMA (auto regressive moving average) model. The general equation of the ARMA model is expressed in Eq. (1).

$$
\begin{aligned}
Y_{t}= & \varphi_{0}+\varphi_{1} Y_{t-1}+\cdots+\varphi_{p} Y_{t-p}+\theta_{1} \varepsilon_{t-1}-\cdots \\
& -\theta_{q} \varepsilon_{t-q}+\varepsilon_{t},
\end{aligned}
$$

where $\varepsilon_{t}$ is independent with an average of 0 for a normal distribution. Thus, $\varepsilon_{t}$ is an error value corresponding to white noise. $\varphi_{0}, \ldots, \varphi_{p}$ and $\theta_{1}, \ldots, \theta_{q}$ are unknown parameters. Averages and distributions of time-series data, which are not uniform with time, cannot be analyzed with the ARMA model. Changes of the average and distribution with time suggest a cause existing within the trend. In this case, the difference according to Eq. (2) removes the timeseries trend, and if the distribution is not uniform with time a logarithm can generally be applied [8].

$\Delta Y_{t}=Y_{t}-Y_{t-1}$.
The proposed model that transforms the time-series data is the ARIMA (auto regressive integrated moving average) model, which can generally represent most of the timeseries data and is expressed by the following Eq. (3) [9].

$$
\begin{aligned}
Y_{t}= & \varphi_{0}+\varphi_{1} \Delta_{d} Y_{t-1}+\cdots+\varphi_{p} \Delta_{d} Y_{t-p}+\theta_{1} \varepsilon_{t-1}-\cdots \\
& -\theta_{q} \varepsilon_{t-q}+\varepsilon_{t} .
\end{aligned}
$$

ARIMA analysis recognizes the varying forms of the time-series present data and allows forecasting with better accuracy. This study utilizes the ARIMA model to forecast the steel scrap supply and compared its forecasted amount with available past data to identify its precision. From the ARIMA model, the forecasted scrap demand is correlated from the steel scrap import amount. However, this study has neglected the social scrap stock that is determined by the lifetime of the stock durables, which may also add to the limitation or uncertainty. Still, the network relationship and trading scheme should still be relevant and could be highly useful in identifying the major constituents of the global scrap trade.

\section{Model Appropriateness and Statistical Errors}

The ARIMA model is expressed with the ARIMA $(p, d, q)$, where $p$ is the number of autoregressive terms, $d$ is the number of differences for stationarity, and $q$ is the number of moving average terms [10]. The parameter estimation for an optimized forecast value and effective dependent variable estimation is provided in Table 2 . In the parameter of the $t$ value, absolute $t$ values greater than 2 will result in a significance of less than 0.05 , which validates the constant $\left(\varphi_{0}\right)$ and numerator $\left(\varphi_{1}\right)$ in the model. Using the present ARIMA model, the steel production and scrap demand were forecasted from the dependent variable of the estimated steel import amount.

To verify the appropriateness of the speculated model with the time-series data, the model was tested with the past data of 2011 and 2012. The goodness-of-fit depends on the minimization of the difference between the actual and estimated values, which can be statistically obtained from the MAPE (mean absolute percentage error) and LijungBox Q [11].

MAPE is calculated using Eq. (4), where $X_{t}$ is the actual value, $F_{t}$ is the forecasted value, and $n$ is the number of years analyzed $(n=24)$, and a value higher than $50 \%$ is conceived to be an inappropriate fit. In the present study, all MAPE values for the various estimated items were found to be lower than the constraint limits of $50 \%$.

$M A P E=\frac{1}{n} \sum_{t=1}^{m}\left|\frac{X_{t}-F_{t}}{X_{t}}\right| \times 100$. 
Table 2 Parameter estimation of steel production (SE is significant error, $t$ is the $t$ value)

\begin{tabular}{|c|c|c|c|c|}
\hline \multirow[t]{2}{*}{ Model } & \multicolumn{4}{|l|}{ Parameters } \\
\hline & Estimate & SE & $t$ & Significance \\
\hline \multicolumn{5}{|l|}{ P_World $(0,1,0)$} \\
\hline Constant $\left(\varphi_{0}\right)$ & $2,720.500$ & 550.071 & 4.946 & 0.000 \\
\hline Numerator $\left(\varphi_{1}\right)$ & 3.111 & 3.830 & 6.719 & 0.000 \\
\hline \multicolumn{5}{|l|}{ P_China $(0,1,0)$} \\
\hline Constant $\left(\varphi_{0}\right)$ & $4,095.000$ & 5.049 & 7.444 & 0.000 \\
\hline Numerator $\left(\varphi_{1}\right)$ & 0.716 & 0.110 & 6.515 & 0.000 \\
\hline \multicolumn{5}{|l|}{ P_USA $(0,1,0)$} \\
\hline Constant $\left(\varphi_{0}\right)$ & $-11,758.998$ & 217.047 & -8.010 & 0.000 \\
\hline Numerator $\left(\varphi_{1}\right)$ & 1.400 & 5.723 & 3.668 & 0.002 \\
\hline \multicolumn{5}{|l|}{ P_India $(0,0,0)$} \\
\hline Constant $\left(\varphi_{0}\right)$ & 3190.865 & 35.056 & 2.596 & 0.029 \\
\hline Numerator $\left(\varphi_{1}\right)$ & 5.211 & 1.635 & 3.195 & 0.005 \\
\hline \multicolumn{5}{|c|}{ P_South Korea $(0,1,0)$} \\
\hline Constant $\left(\varphi_{0}\right)$ & $1,091.850$ & 17.948 & 6.277 & 0.000 \\
\hline Numerator $\left(\varphi_{1}\right)$ & 5.424 & 0.400 & 10.680 & 0.000 \\
\hline \multicolumn{5}{|l|}{ P_Turkey $(0,0,0)$} \\
\hline Constant $\left(\varphi_{0}\right)$ & $1,482.423$ & 15.554 & 8.444 & 0.000 \\
\hline Numerator $\left(\varphi_{1}\right)$ & 1.116 & 0.016 & 71.634 & 0.000 \\
\hline \multicolumn{5}{|l|}{ P_Germany $(0,1,0)$} \\
\hline Constant $\left(\varphi_{0}\right)$ & -370.687 & 8.697 & -2.197 & 0.041 \\
\hline Numerator $\left(\varphi_{1}\right)$ & 2.548 & 0.259 & 9.843 & 0.000 \\
\hline
\end{tabular}

Lijung-Box Q is a verification statistic using the autocorrelation between residual values. If the residuals have a mutual correlation, the applied model is found to be unsuitable for the time-series data. Lijung-Box Q statistics can be calculated by Eq. (5), where $r_{i}$ is the autocorrelation coefficient for the $i$ th year, $k$ is the number of residuals, and $i$ is the year [1st year (1990) to the 24th year (2013)]. In this study, the statistics showed the residuals relationship to be statistically improbable suggesting no significant correlations of the residual values exist, which indirectly verifies the appropriateness of the ARIMA model. The details of the model fitness are shown in Table 3 .

$Q=k(k+2) \sum_{i=1}^{m}\left(\frac{r_{i}^{2}}{k-i}\right)$.

Thus, by verifying the 2011 and 2012 estimates with the actual using the $t$ test, the estimates were found to be applicable for the present study. The detailed calculation of the $t$ test is provided in Table 4. $T$ test is an analysis method to verify the difference in the mean between two groups or values such as the difference between the forecasted estimate and the actual of 2011 and 2012. A significant difference between the actual and the estimate suggests a deviation from appropriateness of the model.

\section{Results and Discussions}

\section{Steel Scrap Commodity Trading Trend}

Figure 1 shows the amount of steel scrap exported from various countries from 1990 to 2013 in the present study. Due to the complexity and number of countries exporting steel scrap, the top countries between 2011 and 2013 have been selected with China (23rd) and Republic of Korea (47th) added.

The USA exports the most scrap to the global market with its continued excess scrap supply produced from infrastructure rebuilding and availability of obsolete scrap from consumer goods. Germany along with Japan also export significant amounts of scrap, but Japan seems to limit its market to the Asian countries close-by, where the logistics is favorable. Although China continues to produce more than half of global steel production, the country continues to expand and develop infrastructure, which has yet to be outdated, and thus consumes most of its domestic obsolete scrap without excess to export to other countries. Republic of Korea, similar to China, consumes most of its generated internal scrap, which was more than $20 \mathrm{MT}$ in 2012, and is one of the largest importers of scrap for the 
Table 3 Results of model fitness test

Table 4 Results of the $t$ test ( $t$ is the $t$ value)

Fig. 1 Annual exported steel scrap amount for various countries. Top 5 scrap exporters for 2011-2013 were selected with China (23rd) and Rep. of Korea (47th) added

\begin{tabular}{lrlll}
\hline Model & MAPE & $\begin{array}{l}\text { Model fit Statistics } \\
\left(\text { Standard } R^{2}\right)\end{array}$ & \multicolumn{2}{l}{ Lijung-Box Q } \\
\cline { 4 - 5 } & & 0.710 & 24.105 & 0.087 \\
\hline P_World $(0,1,0)$ & 9.187 & 0.165 & 10.951 & 0.859 \\
P_China $(0,1,0)$ & 5.486 & 0.770 & 16.097 & 0.586 \\
P_USA $(0,1,0)$ & 5.082 & 0.381 & 21.350 & 0.126 \\
P_India $(0,0,0)$ & 19.074 & 0.825 & 14.438 & 0.700 \\
P_South Korea $(0,1,0)$ & 2.570 & 0.997 & 19.092 & 0.386 \\
P_Turkey $(0,0,0)$ & 2.213 & 0.843 & 14.685 & 0.683 \\
P_Germany $(0,1,0)$ & 3.140 & & & \\
\hline
\end{tabular}

\begin{tabular}{|c|c|c|c|c|}
\hline Model & Actual (kt) & Estimate (kt) & $t$ & Significance \\
\hline \multicolumn{5}{|c|}{ P_World $(0,1,0)$} \\
\hline 2011 & 668.3 & 622.2 & 4.293 & 0.146 \\
\hline 2012 & 669.4 & 640.7 & & \\
\hline \multicolumn{5}{|c|}{ P_China $(0,1,0)$} \\
\hline 2011 & 197.2 & 195.3 & -0.659 & 0.629 \\
\hline 2012 & 201.3 & 210.5 & & \\
\hline \multicolumn{5}{|c|}{ P_USA $(0,1,0)$} \\
\hline 2011 & 59.0 & 55.6 & 10.634 & 0.60 \\
\hline 2012 & 59.7 & 55.6 & & \\
\hline \multicolumn{5}{|c|}{ P_India $(0,0,0)$} \\
\hline 2011 & 53.8 & 54.4 & -1.797 & 0.323 \\
\hline 2012 & 57.2 & 59.5 & & \\
\hline \multicolumn{5}{|c|}{ P_South Korea $(0,1,0)$} \\
\hline 2011 & 34.8 & 32.7 & 2.169 & 0.275 \\
\hline 2012 & 34.6 & 33.8 & & \\
\hline \multicolumn{5}{|c|}{ P_Turkey $(0,0,0)$} \\
\hline 2011 & 27.0 & 28.0 & -2.240 & 0.267 \\
\hline 2012 & 28.4 & 28.8 & & \\
\hline \multicolumn{5}{|c|}{ P_Germany $(0,1,0)$} \\
\hline 2011 & 20.2 & 18.7 & 3.288 & 0.173 \\
\hline 2012 & 19.6 & 18.7 & & \\
\hline
\end{tabular}

(unit: 1000 ton)

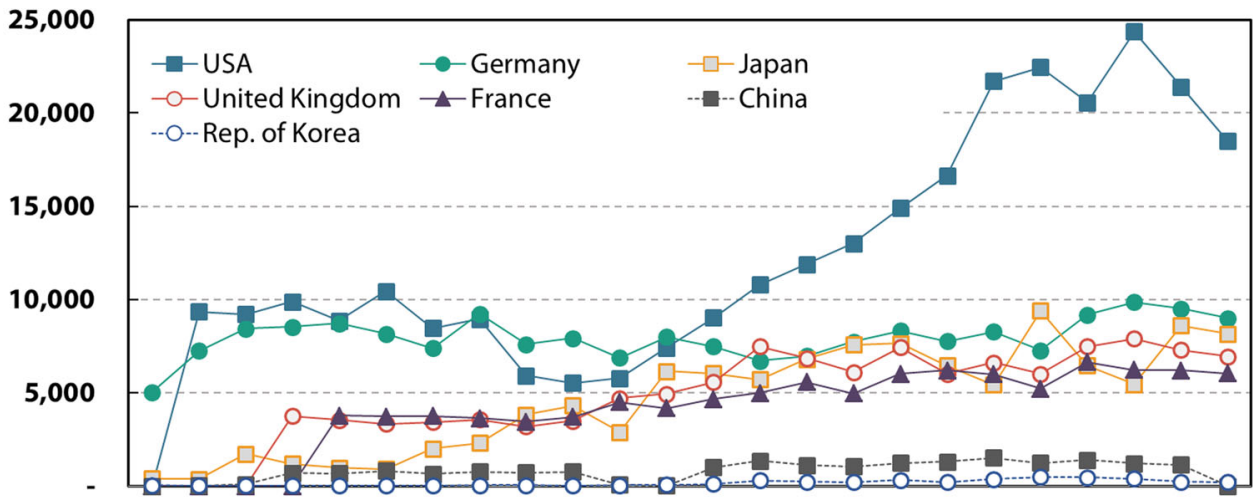

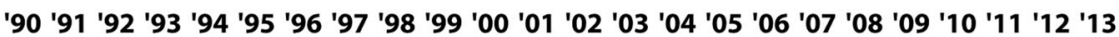


Fig. 2 Annual imported steel scrap amount for various countries. Top 5 scrap importers from 2011 to 2013 were selected with US (9th) and Japan (31st) added

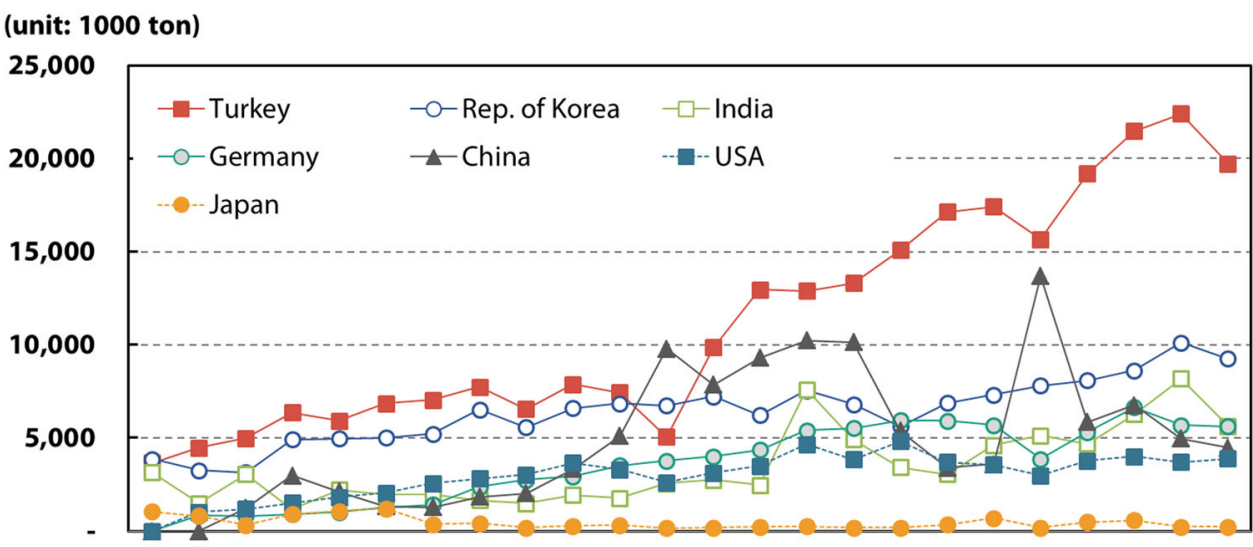

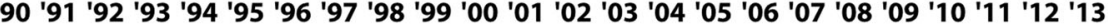

EAF and BOF producing more than $60 \mathrm{MT}$ of steel in 2012 resulting in minimal steel scrap export to other countries.

Figure 2 shows the steel scrap importing countries with respect to the year. The top 5 countries between 2011 and 2013 were selected with the USA (9th) and Japan (31st) added. Turkey, which is concentrated with EAFs and produces mostly plain carbon long product steels, imports the largest amount of steel scrap. It can be speculated that the concentrations of EAF stems from its geological position with respect to Russia and Ukraine with significant surplus of scrap and the frequent earthquakes in Turkey, which can put significant pressure on the design specifications of an integrated steel facility. Thus, a smaller efficient EAF route with the capability of rapid shutdowns and start-ups, while maintaining the production ability to produce plain carbon long products is warranted. However, with Turkey's continued reliance in EAF technology, it will be necessary to maintain a steady energy power grid system and cheap energy sources including nuclear and hydroelectric. Turkey's scrap import particularly expanded from 2002 and continues a steep increase from pre2002 levels, as it becomes one of the most significant sources for long products to export into the European Union. Republic of Korea is the second largest importer of steel scrap to support its EAF production amounting to approximately $25 \mathrm{MT}$ in 2012 and its incremented usage of scrap to more than $20 \%$ in the $\mathrm{BOF}$ to indirectly lower the $\mathrm{CO}_{2}$ emissions in the integrated steel mill [12].

Compared to other countries, Germany not only exports significant amounts of scrap, but also imports the commodity in significant quantities as well. Considering Germany's product ranges of steel and its propensity for selling higher-value added steel products, the use of lowgrade obsolete steel scrap that can contain significant amounts of impurities, which affect product quality, are traded to countries such as Turkey producing long products with less stringent quality, while cleaner and leaner scrap at a higher cost is imported to Germany from other countries to produce higher-value added products. China imported significant amounts of scrap in 2009 after the Beijing Olympics, when social infrastructure investment increased [13]. However, with the financial crisis expanding from 2008 to 2009, it can be speculated that the utilization of excess hot metal and pig iron ingots into the EAF was economically more favorable [14]. It is also remarkable to observe the low amount of steel scrap imports into China even though the global production of steel is dominated by China. This indirectly suggests that the availability of hot metal is so extensive that the scrap utilization ratio in the EAF and BOF compared to other countries in the furnaces is comparatively lower. Past work regarding hot metal utilization has shown an optimal hot metal input into the EAF to be approximately $30 \%$ of the charge. Although unconfirmed, domestic scrap generation and imported scrap supply suggest the BOF in China utilizes approximately $10 \%$ of scrap in the charge compared to the 20-25\% scrap charge in the US and likely $25-30 \%$ hot metal and pig iron into the EAF. Compared to the availability of domestic scrap, there is much more excess hot metal or pig iron to charge in the EAF for China [15].

Even with the abundance of domestic steel scrap in the USA, outside scrap is imported, where the freight costs are not significant. Most of the scrap imported by the USA is from Canada, which supplies some of the integrated steel mills in the Northeast and Midwest USA. Some of the imported scrap is from Mexico, which supplies some of the EAF mills in the Southern regions of the USA.

Although the scrap import amount by India is not as much as Turkey or Rep. of Korea, there seems to be significant potential of steel scrap demand once power and infrastructure develop within the country. Many steel companies in India, which does not have a steady and reliable power grid throughout the country, utilize carbonbased integrated steel mills or an additional direct reduction technology through the rotary kiln process [16]. 
The overall trend of scrap trade for the countries highlighted in the present study seems to indicate an increase in the steel scrap consumption, which corresponds to the steel production output and will need to be matched with the steel scrap available in the global market. The estimated supply and consumption of steel scrap is provided in a subsequent section, but seems to suggest that scrap will be sustainable for utilization in steel processing with additional leverage provided by DRI and HBI as a clean scrap substitute.

\section{Scrap Trading Network Analysis}

Steel scrap trading network analysis involves identifying the various countries that import and export the commodity and building relationships among scrap trading countries with an emphasis on determining the dominant suppliers and consumers through a specific centrality index. During the period of 1990-2013, the cumulative trade volumes of countries exceeding 5 and $2.5 \mathrm{MT}$ have been taken into account for export and import of the present study, respectively. Figure 3 shows the global steel scrap export relationship between countries expressed as nodes, and the linked lines indicate the connection between the countries with the thickness of the lines and mode size corresponding to greater trade volumes. The arrows indicate the export volume direction from the country of interest to a different country. The greatest cumulative amount of scrap export within the period of interest was found to be from the USA, which resulted in the largest nodes of the network relationship.

Table 5 provides the total cumulative amount of steel scrap export in the order of highest volume of trade in tons, and Table 6 shows the highest volume of country-tocountry cumulative scrap export amount between two individual countries, where the trade between the USA and the Rep. of Korea led with a 53 MT total from 1990 to 2013. The USA has not only exported the highest amount
Fig. 3 Global scrap export network analysis of various trading countries with cumulative scrap trading amounts in excess of 5 MT from the period of 1990-2013. Larger nodes and thicker lines indicate a dominance in the scrap trade between the respective countries

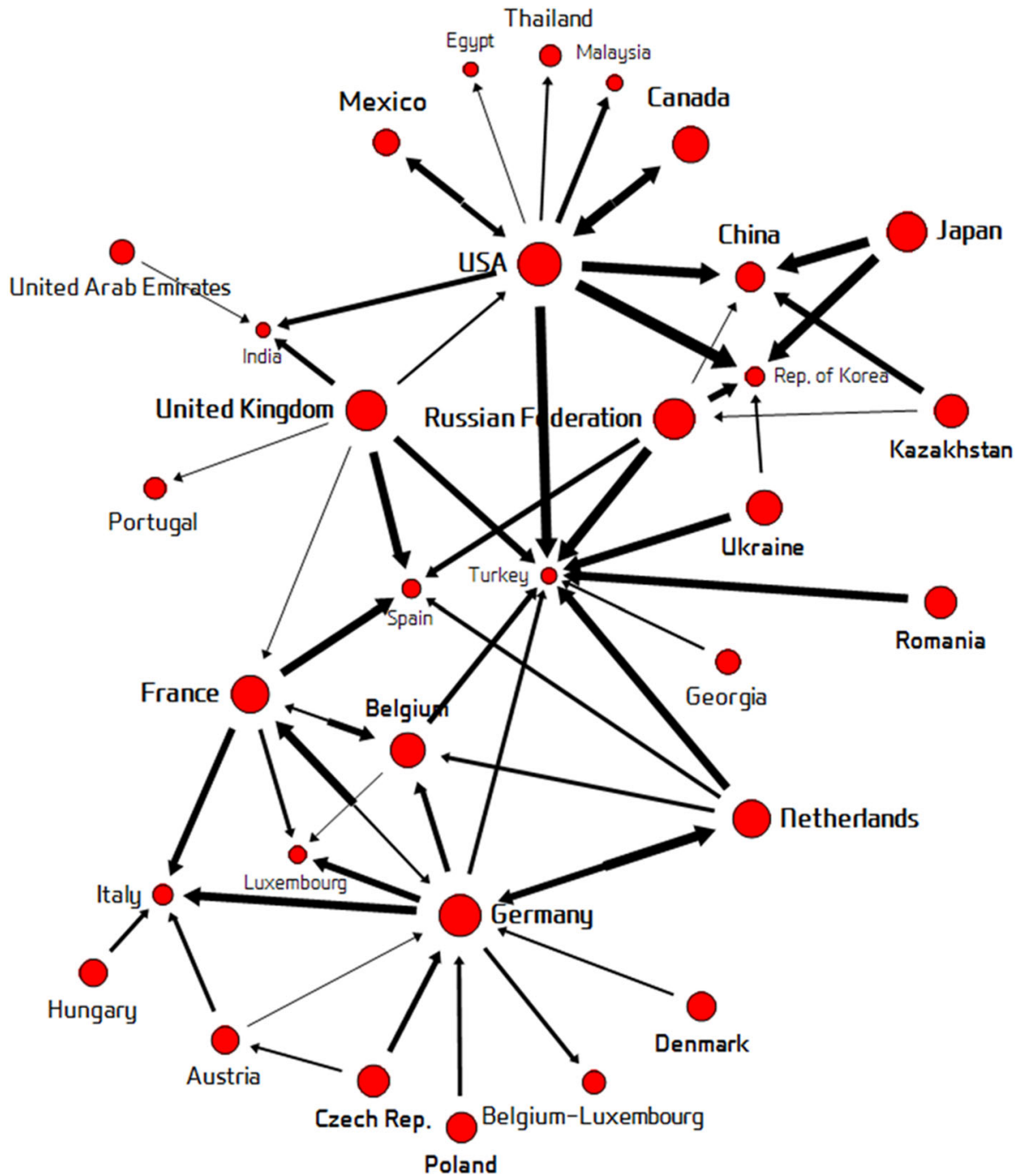


Table 5 Total cumulative steel scrap export amount from 1990 to 2013 of the top 10 countries in the order of greatest volume

\begin{tabular}{llr}
\hline No. & Exporting country & Weight $(\mathrm{kt})$ \\
\hline 1 & USA & $294,969.0$ \\
2 & Germany & $191,201.9$ \\
3 & Russian Federation & $117,052.7$ \\
4 & United Kingdom & $115,684.4$ \\
5 & Japan & $110,746.1$ \\
6 & France & $99,411.1$ \\
7 & Netherlands & $89,321.7$ \\
8 & Canada & $65,508.9$ \\
9 & Ukraine & $56,099.5$ \\
10 & Belgium & $41,413.8$ \\
\hline
\end{tabular}

Table 6 Cumulative steel scrap amount between countries exported from 1990 to 2013

\begin{tabular}{llll}
\hline No. & Exporting country & Importing country & Weight $(\mathrm{kt})$ \\
\hline 1 & USA & Rep. of Korea & $53,186.5$ \\
2 & Japan & Rep. of Korea & $50,360.9$ \\
3 & Canada & USA & $49,091.5$ \\
4 & USA & Turkey & $48,389.8$ \\
5 & USA & China & $46,802.6$ \\
6 & Japan & China & $44,600.8$ \\
7 & Russian Federation & Turkey & $38,464.2$ \\
8 & Germany & Netherlands & $38,115.5$ \\
9 & Germany & Italy & $36,976.5$ \\
10 & Ukraine & Turkey & $35,484.3$ \\
\hline
\end{tabular}

The top 10 country-to-country cumulative export amount in the order of greatest volume is provided

of steel scrap compared to any other country, but also ships to a wide variety of countries. This diversity of steel scrap trading indicates a robust logistic system of scrap trade in the USA and better trade portfolio that can better sustain the cyclic characteristic of the steel industry in an economic downturn. Germany is not only a major supplier of steel scrap within the EU, but also seems to receive scrap from France, Denmark, Poland, and the Czech Republic. Turkey's consumption of steel scrap seems to indicate a wide source from various countries to satisfy the EAF's increased productivity and its consumption for scrap. The major scrap suppliers for Turkey were the USA, Russian Federation, Ukraine, Netherlands, and Romania.

From the steel scrap export network analysis and the number of links between countries, the major suppliers of steel scrap are the USA and Germany with a cumulative steel scrap amount of 294 and 191 MT, respectively. It is apparent that countries such as the USA, Germany, Russian Federation, and other fairly well-developed ones, with significant obsolete scrap retrieved from infrastructure rebuilding and waste consumer goods, have also major scrap logistics centers allowing an efficient processing of scrap and subsequent shipment to the various customers. The detailed sub-divided network analysis of 5-year periods starting from 1995 to 2013 is shown in Fig. 4a and b.

The USA, Germany, and United Kingdom continue to be within the top five scrap suppliers within the period of interest. This trend is likely to continue into the near future as developed countries are likely to provide a steady supply of obsolete scrap and consumer goods scrap considering consumer spending in the developed countries is typically much higher than the developing and under-developed countries. The cumulative quantity of scrap within the 5 -year periods is also provided within Fig. 4. The top three individual scrap export quantity is shown.

Figure 5 shows the network relationship of global imported steel scrap among the various countries. Similar to the export network relationship diagram in Fig. 3, the nodes and links represent the country and trading connections between countries. Larger nodes and thicker lines indicate higher volume of trade. Table 7 provides the total cumulative amount of steel scrap import in the order of highest volume of trade in tons, and Table 8 shows the highest volume of country-to-country cumulative scrap import amount between two individual countries, where the trade between the USA and the Rep. of Korea led with a 60 MT total from 1990 to 2013. Within the period of 1990-2013, the cumulative amount of steel import is greatest in Turkey with Rep. of Korea, Spain, China, and Italy following. Both Turkey and Spain are concentrated in EAF technology, which rely on scrap. Korea is not only concentrated in the integrated steelmaking route at about 44 MT, but also produces roughly 27 MT of steel through the EAF route as well. China also imports significant amount of scrap, but does not directly correspond to its total production amount. Either the available obsolete domestic scrap can provide enough scrap for its needs or hot metal use is high. China receives its outside scrap sources from nearby Japan and the Russian Federation with the USA also providing significant amounts of scrap.

The network relationship of scrap imports within a 5-year period starting from 1995 is shown in Fig. 6. The larger nodes of Turkey, Spain, Rep. of Korea, and Italy show the major consumers of steel scrap in the period of 1995-1999. Turkey shows the changes and additions of the steel scrap amount from different countries as its EAF production capacity increases during the sub-periods. From 1995 to 1999, Turkey increased its scrap import significantly from the Russian Federation and Ukraine. It should be noted that for some countries such as Rep. of Korea and Japan, the amount of steel exported from Japan to Korea and the amount of steel imported from Korea to Japan do 


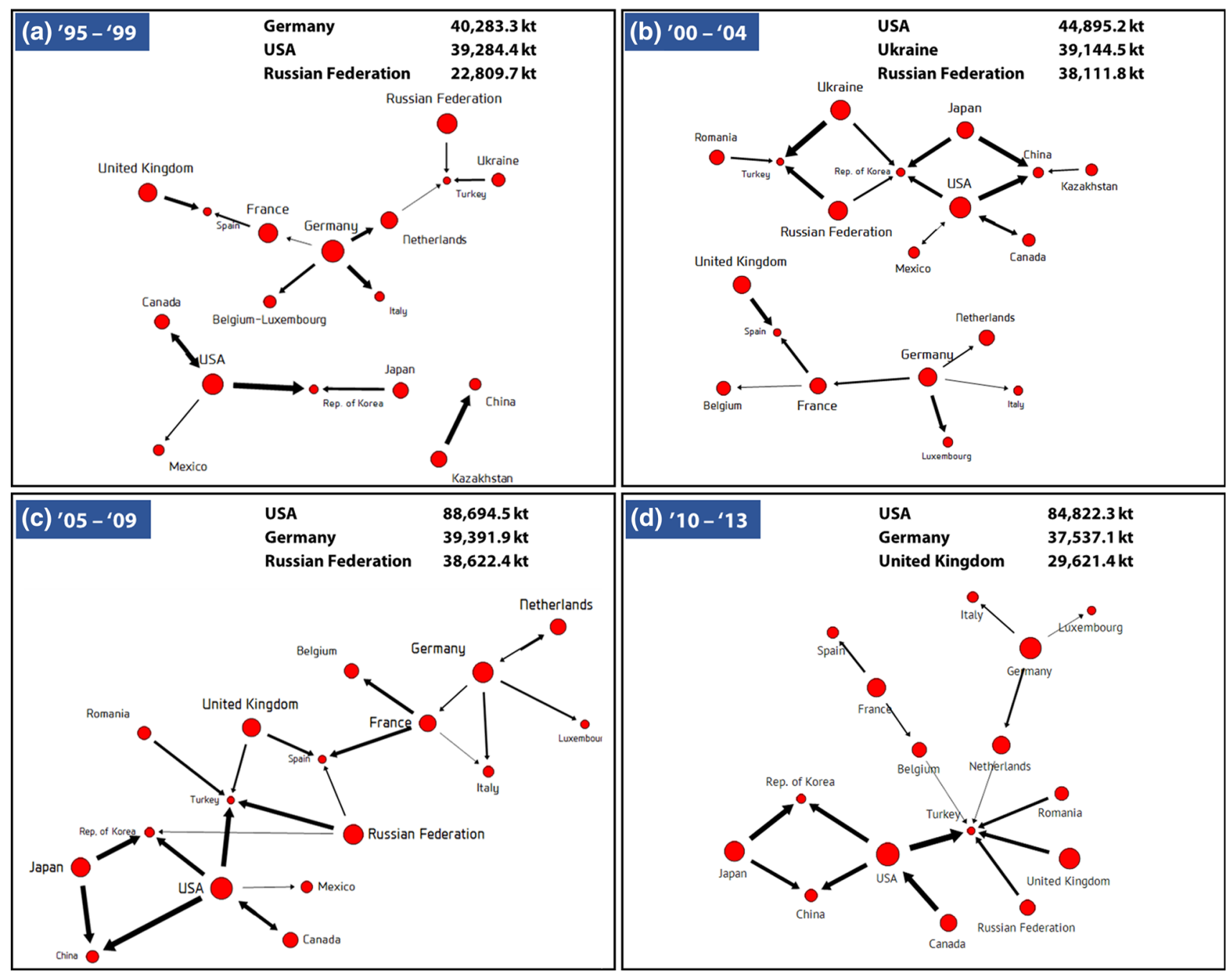

Fig. 4 Steel scrap export network analysis of countries within a period of 5 years starting from 1995. a 1995-1999, b 2000-2004, c 2005-2009, and d 2010-2013

not exactly match during the perceived identical periods. This discrepancy may be an inadvertent error in the data from the UN or the difference between shipped date and date received. Scrap trade between Canada and the USA is also active with more than 10 MT exported to the USA from Canada over each 5-year period.

As can be verified, the network relationship and the amount of steel scrap traded between countries have become more complex. This complexity would require a more efficient and robust logistics operation for optimum inventory control and competitive pricing. Diversity in the scrap supply is maybe needed for countries, where existing network relationships rely on only a few sources.

Republic of Korea has consistently been a major consumer of steel scrap especially from the USA and Japan, but as electricity costs increase significantly, the EAFbased process may become less cost-effective and a slowdown in the consumption of scrap may occur. However, the EAF product ranges have been expanding toward the higher-value added steel products and through utilization of DRI/HBI and higher quality steel scrap, the EAF may find other means of effectively competing with the integrated steel mills.

Centrality Analysis of Steel Scrap Commodity Between Countries

To identify the major players of the steel scrap trade, the network analysis and subsequent centrality of countries must be identified. According to the Katz status index, the centrality of a node (country) or the dominance of a scrap trading country within the scrap network relationship is identified, and unlike the typical degree centrality analysis, the Katz status index not only identifies the country with 


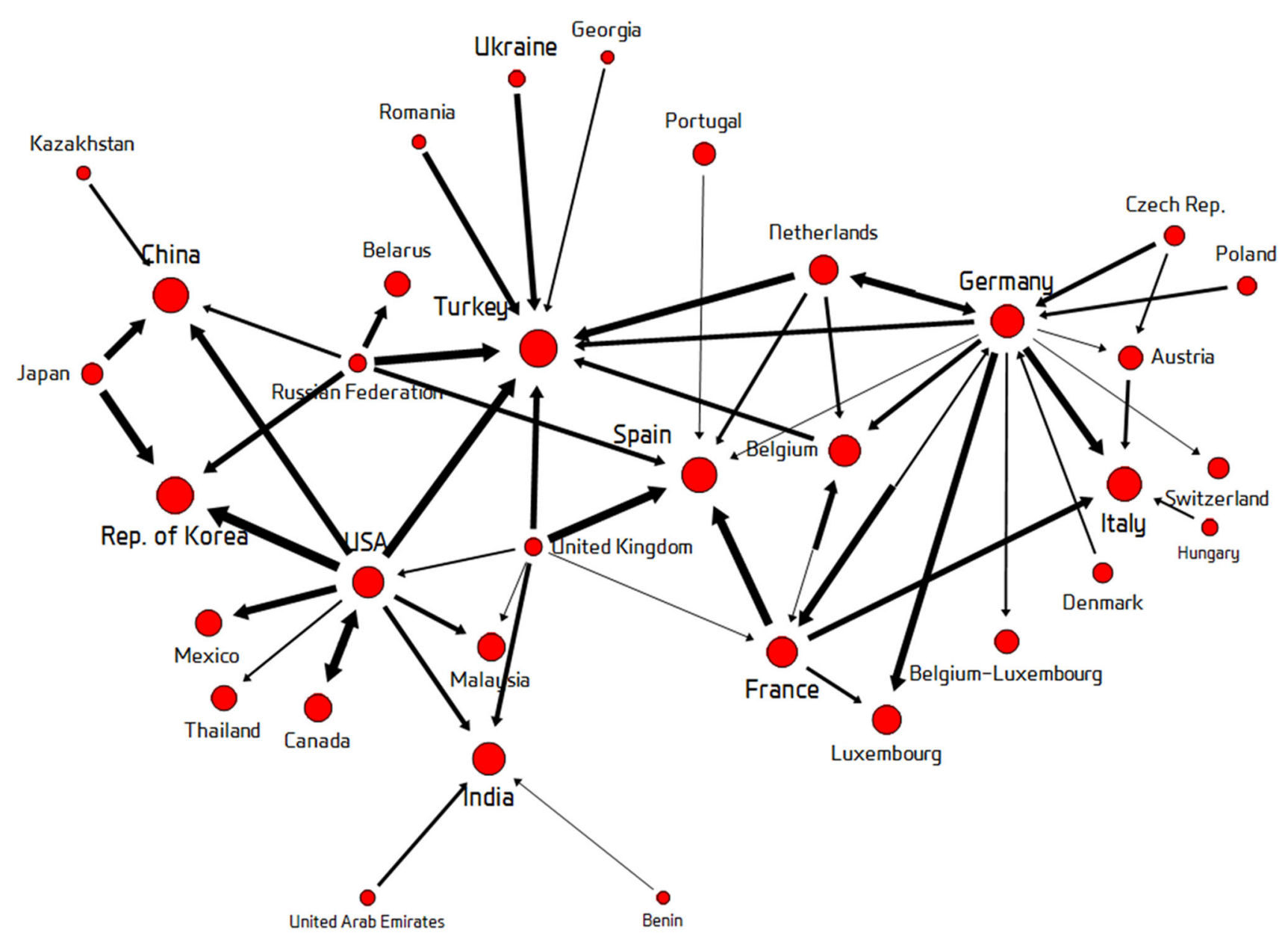

Fig. 5 Global scrap import network analysis of various trading countries with cumulative scrap trading amounts in excess of 2.5 MT from the period of 1990-2013. Larger nodes and thicker lines indicate a dominance in the scrap trade between the respective countries

Table 7 Total cumulative steel scrap import amount from 1990 to 2013 of the top 10 countries in the order of greatest volume

\begin{tabular}{llr}
\hline No. & Importing country & Weight $(\mathrm{kt})$ \\
\hline 1 & Turkey & $271,078,232.2$ \\
2 & Rep. of Korea & $154,169,588.0$ \\
3 & Spain & $131,122,903.8$ \\
4 & China & $121,836,781.8$ \\
5 & Italy & $99,813,652.4$ \\
6 & Germany & $86,564,936.8$ \\
7 & India & $83,080,894.2$ \\
8 & USA & $71,125,415.0$ \\
9 & Belgium & $57,356,779.9$ \\
10 & France & $53,315,100.5$ \\
\hline
\end{tabular}

which it trades, but also considers the effect of non-trading countries within the calculated estimates. The Katz status index can be calculated by Eq. (6) [17].
Table 8 Cumulative steel scrap amount between countries imported from 1990 to 2013

\begin{tabular}{llll}
\hline No. & Exporting country & Importing country & Weight (kt) \\
\hline 1 & USA & Rep. of Korea & $60,395.3$ \\
2 & USA & Turkey & $53,728.5$ \\
3 & Japan & Rep. of Korea & $50,525.1$ \\
4 & Canada & USA & $50,231.7$ \\
5 & Russian Federation & Turkey & $40,360.8$ \\
6 & United Kingdom & Spain & $37,353.2$ \\
7 & USA & Canada & $36,044.6$ \\
8 & France & Spain & $35,152.1$ \\
9 & Japan & China & $31,458.5$ \\
10 & USA & China & $31,055.9$ \\
\hline
\end{tabular}

The top 10 country-to-country cumulative import amount in the order of greatest volume is provided

Katz_ $C_{i}=\sum_{k=1}^{\infty} \sum_{j=1}^{n} a^{k}\left(A^{k}\right)_{j i}$, 

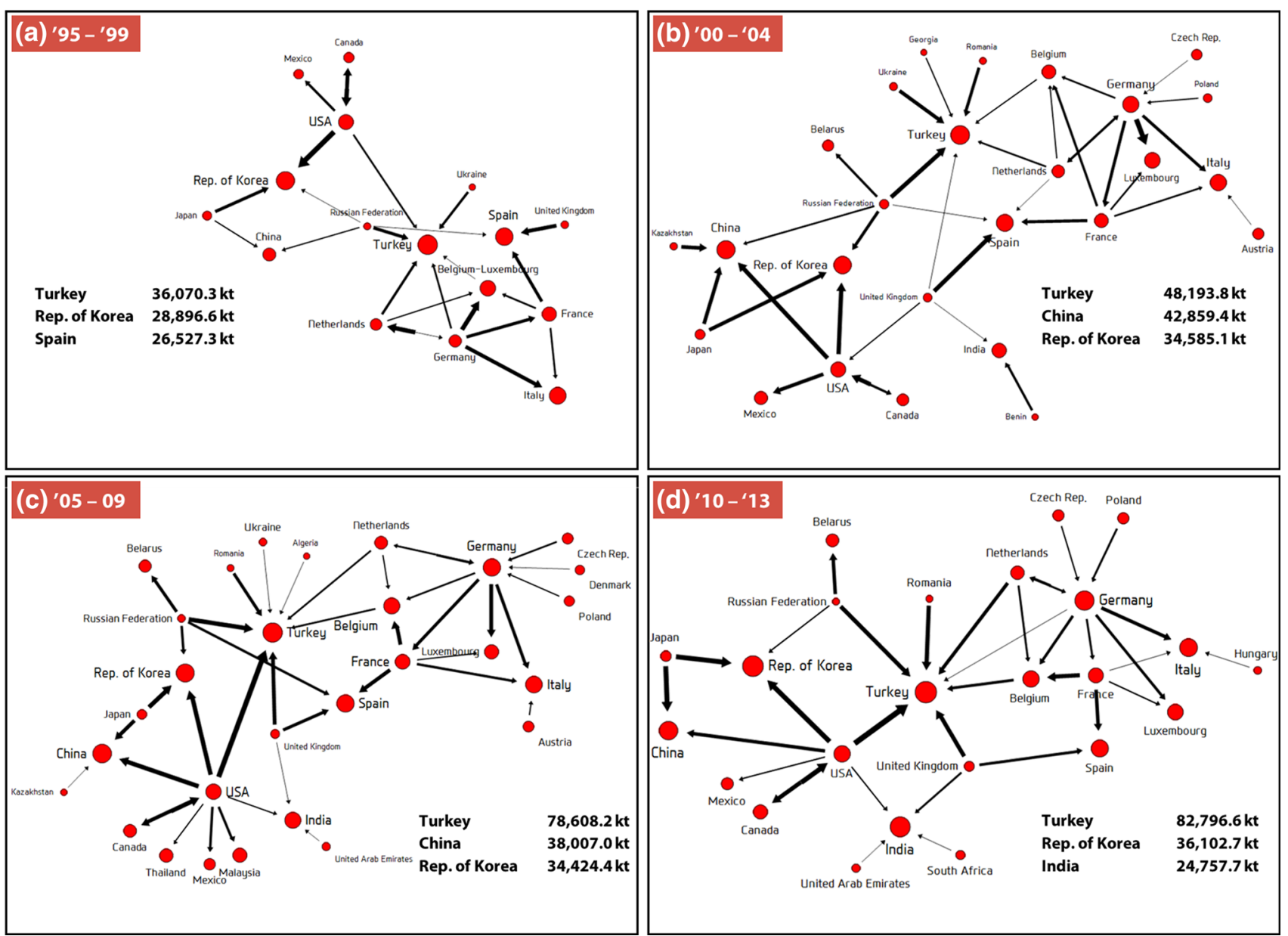

Fig. 6 Steel scrap import network analysis of countries within a period of 5 years starting from 1995. a 1995-1999, b 2000-2004, c 2005-2009, and d 2010-2013

where $A$ is the number of affiliated nodes connected to the target node, $k$ is the number of steps to reach target country for import and export, $i$ is the export country, $j$ is the import country, and $a$ is the decay factor, which is greater than or equal to 0 and less than or equal to 1 . With higher $k$ values, $a^{k}$ value decreases and without a direct trade relationship, the effect on $i$ would be small.

The Katz status index for centrality obtained from the export and import analysis is provided in Table 9. The centrality of the export and import network analysis mapping corresponds to the out-status centrality and in-status centrality, respectively. For the export relationship network, the USA has an index of 1.253 indicating a high centrality for export of steel scrap to Germany, United Kingdom, Canada, and the Russian Federation. The top 2 high centrality countries including the USA and Germany seem to have a high centrality and dominate the steel scrap market with its continued and steady scrap supply. Beyond the top 2, the amount of scrap supply seems to be comparatively much lower than the top 2 suppliers in the global steel scrap market and have fewer networks to supply. For the import relationship network, Turkey showed the highest Katz status index value for centrality at 2.032, which is almost twice that of the 2nd highest ranking centrality of Korea at 1.196. This significant difference in the index value seems to be due to the number of direct and indirect relationships that Turkey has with its suppliers from outside the country as it imports steel scrap. Thus, Turkey not only imports large amounts of scrap, but also has a relatively diversified scrap network for importing the commodity. Korea, Spain, China, and Italy follow Turkey for the centrality analysis, as observed in Table 9.

\section{Scrap Forecasting Using Time-Series Analysis}

From the relationship analysis between imported scrap and steel production, a direct correlation could be observed in the world, China, USA, India, Korea, Turkey, and Germany, but Japan did not show a high correlation of the imported scrap and steel production according to the 
Table 9 Centrality of the export and import network analysis mapping using the Katz status index

\begin{tabular}{|c|c|c|c|c|}
\hline \multirow{2}{*}{$\frac{\text { No. }}{1}$} & \multicolumn{2}{|c|}{ From export network analysis (Out-Status Centrality) } & \multicolumn{2}{|c|}{ From import network analysis (In-Status Centrality) } \\
\hline & USA & 1.253 & Turkey & 2.032 \\
\hline 2 & Germany & 0.957 & Rep. of Korea & 1.196 \\
\hline 3 & United Kingdom & 0.543 & Spain & 0.969 \\
\hline 4 & Canada & 0.534 & China & 0.829 \\
\hline 5 & Russian Federation & 0.515 & Italy & 0.800 \\
\hline 6 & France & 0.475 & Germany & 0.625 \\
\hline 7 & Netherlands & 0.458 & India & 0.592 \\
\hline 8 & Japan & 0.440 & USA & 0.555 \\
\hline 9 & Ukraine & 0.237 & Belgium & 0.505 \\
\hline 10 & Belgium & 0.204 & France & 0.449 \\
\hline
\end{tabular}

The top 10 countries for the export and import is provided as out-status and in-status centrality, respectively

Fig. 7 Global steel production with the scrap demand plotted with the estimated forecast of scrap demand using the ARIMA model up to 2018

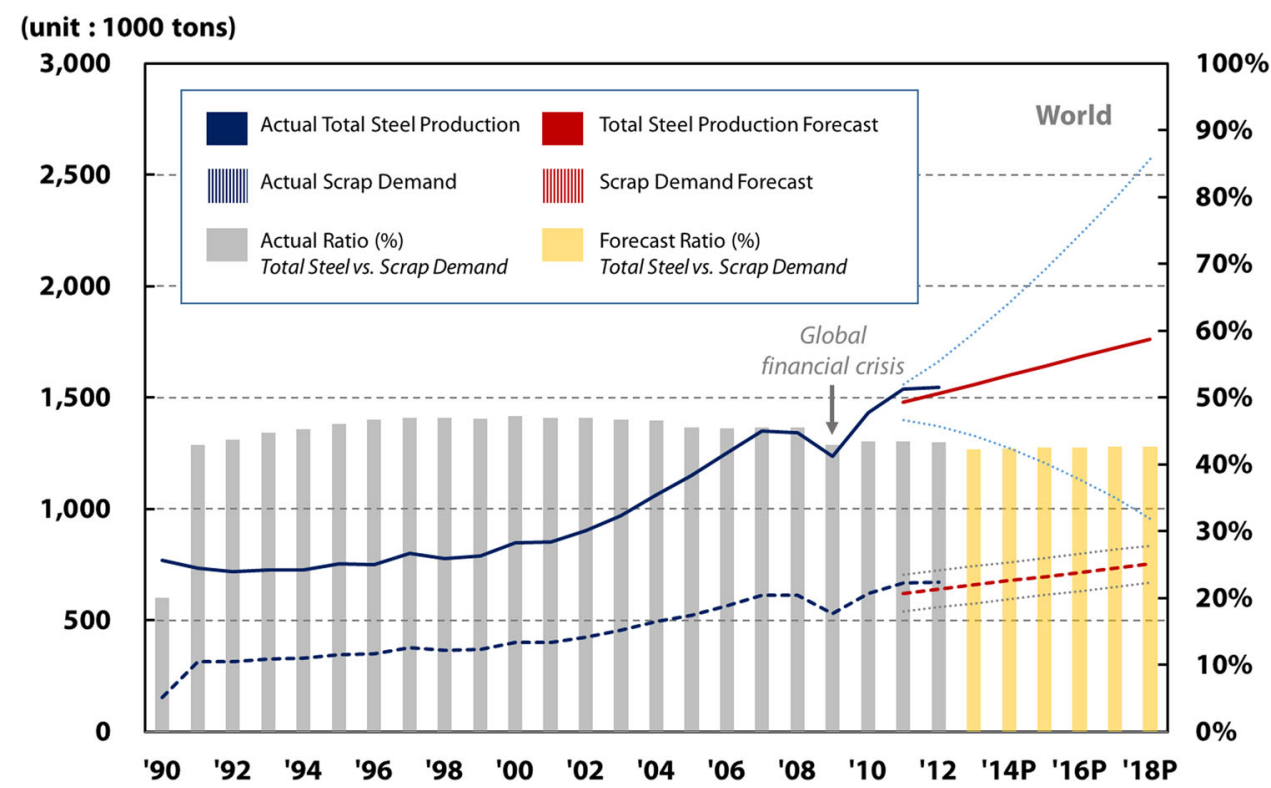

correlation coefficient of 0.32 using Pearson's model. The $p$ value indicating statistical significance of the correlation coefficient was found to be 0.16 , which is much higher than the typical $p$ value of 0.05 and less for meaningful correlations. This is likely due to the low amount of scrap import compared to the total steel production.

From the steel production data obtained from the World Steel Association, the amount of steel produced through the integrated steel and the electric arc furnace can be ascertained. If it is assumed that the EAF process route utilizes $100 \%$ scrap and the integrated process route utilizes $20 \%$ scrap, the total amount of scrap demand for the countries of interest can be estimated. Although some EAF processes do utilize other sources of iron-bearing materials such as DRI, HBI, and even hot metal, the present study assumes scrap only-based EAF process, except for China and India. For the integrated steel route, there seems to be significant differences between the various countries, and an average of $20 \%$ was assumed. North America typically utilizes 20-25\% scrap in the BOF, while Rep. of Korea and Japan utilize approximately 15-20\% and China seems to use less than $15 \%$. China seems to combine significant amounts of hot metal and pig iron into the EAF feed, and thus a $70 \%$ scrap charge was assumed and for the BOF scrap additions were assumed to be $10 \%$. India seems to combine significant amounts of DRI into the EAF feed and thus a $70 \%$ scrap charge was assumed and for the BOF scrap additions were also assumed to be $10 \%$.

Figure 7 shows the world steel scrap utilization or consumption per year. An increase in the steel scrap use correlated with overall steel production is shown. The 2009 dip shows the effect of the global financial crisis and its impact on the overall consumption of steel scrap and the production. The scrap demand seems to correlate well with 

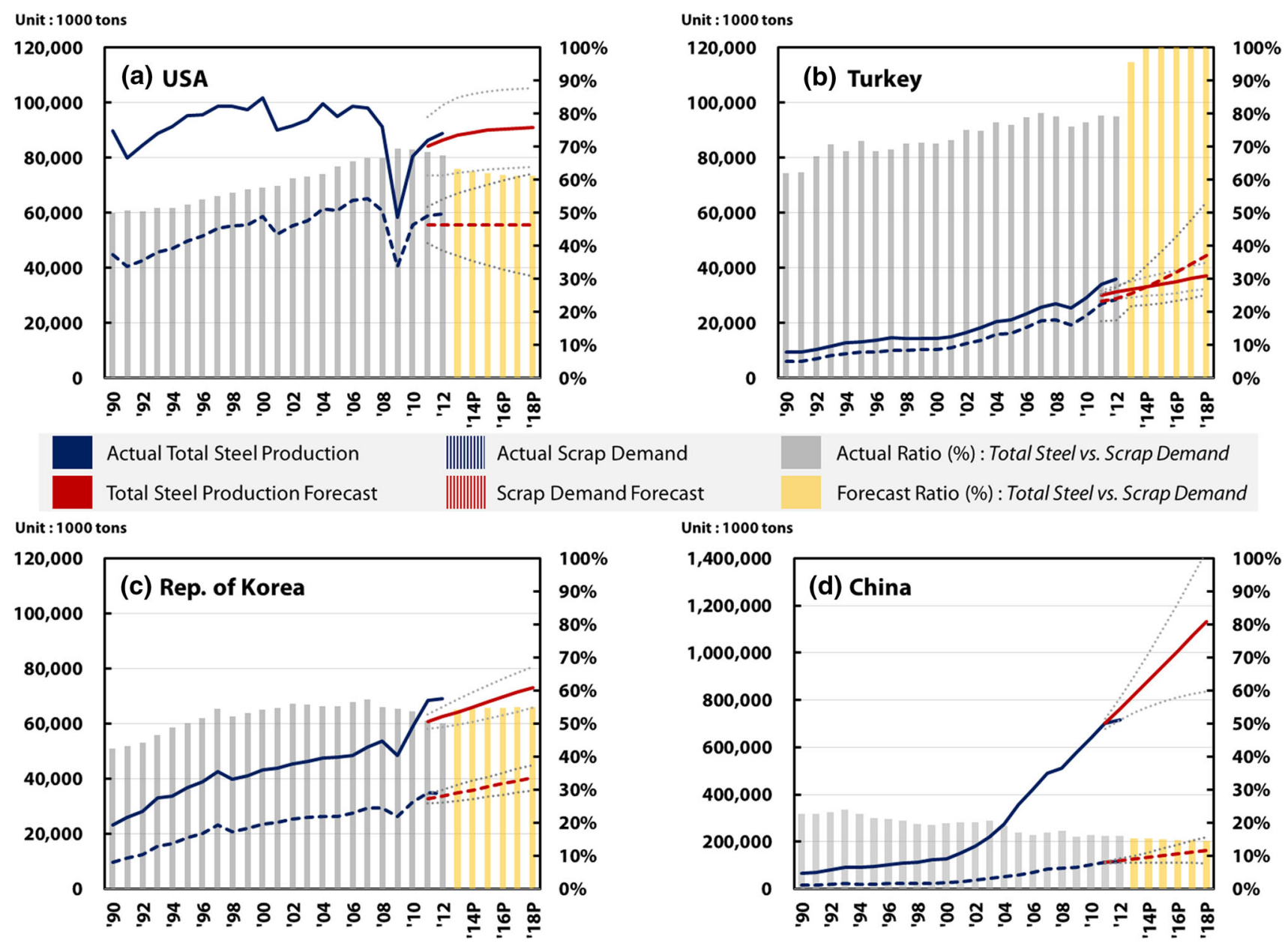

Fig. 8 Steel production with the scrap demand plotted with the estimated forecast of scrap demand using the ARIMA model up to 2018 for a US, b Turkey, c Rep. of Korea, and d China

the global steel production and the forecast also follows similar patterns. A detailed analysis of the USA, Turkey, Rep. of Korea, and China is provided in Fig. 8a-d. This depth of impact in the manufacturing sector and steel production seems to vary among countries. Developed countries such as the USA had significant impact on the steel sector and hence a large drop in the production and also use of scrap was observed. Rep. of Korea, China, and Turkey had less of an impact. The forecasted amount of steel scrap consumption in 2018 is expected to be approximately 750 MT globally with China to be approximately 200 MT. Scrap utilization in the developed countries of USA and Germany have relatively consistent levels of scrap use at 60 and $20 \mathrm{MT}$, respectively, in 2013, and the forecasted projections to 2018 seem to be at similar levels to the present consumption levels. Rep. of Korea is expected to continue its increasing trend of scrap use for steel production with the construction of the 3rd BF for Hyundai Steels and the increased scrap ratio at POSCO to lower carbon foot print in the integrated steel route as the carbon tax levy takes effect in 2015 of January. All of the forecasted trends using the ARIMA model lie within the maximum and minimum ranges of error provided in the model calculations. The overlapped region for the estimated scrap usage and also the forecasted data seem to correlate well and indicate a relatively good fit.

\section{Conclusions}

Scrap sustainability in the near future and steel productivity can be optimized by understanding the total flow of steel scrap across the various countries. This study provides a time-series scrap analysis of import and export data from various countries within the period of 1990-2013. Visualization of the scrap network relationship between trading countries allows an intuitive understanding of the global scrap exchange and the main trading countries for imports and exports. By building a network analysis of the export commodity flows, a high centrality using the Katz status 
index for exporting steel scrap from the USA and Germany at 1.253 and 0.957 , respectively, was observed. From the network analysis of the import commodity flows, a high centrality using the Katz status index for importing steel scrap by Turkey and Rep. of Korea at 2.032 and 1.196, respectively, was observed. In the Katz centrality analysis, not only is the direct relationship considered, but also the indirect relationship between trading countries is used. Countries such as the USA and Germany ship significant amounts of scrap and also have comparatively high centrality. However, the Russian Federation and UK also ship significant amounts of scrap, but the number of countries shipped to is limited compared to the USA and Germany, which suggests possible expansion of its trade network to be possible if logistics can be optimized. This expansion will allow greater flexibility in the scrap supply and also increase availability in the global scrap market, increasing the utilization of scrap and also the sustainability of the steel industry. Steel forecasting based on the time-series analysis showed global steel demand in 2018 to be approximately $750 \mathrm{MT}$ with $1.75 \mathrm{BT}$ expected for overall steel production, which suggests scrap supply should match the demand.

Acknowledgments This study was partially supported by the Brain Korea 21 PLUS (BK21 PLUS) Project at the Division of the EcoHumantronics Information Materials and the National Research Foundation of Korea Grant funded by the Korean Government (NRF-2013-11-2166).

\section{References}

1. AISI http://www.steel.org/Sustainability/Steel\%20Recycling.aspx. Accessed 2014 Nov 20
2. Fruehan RJ (1998) The making, shaping and treating of steel. AISE Steel Foundation, Pittsburgh

3. Lee B, Sohn I (2014) Review of innovative energy savings technology for the electric arc furnace. JOM 66(9):1581-1594

4. Steel Recycling Institute. http://www.recycle-steel.org/Recy cling\%20Resources/Buy\%20Recycled.aspx. Accessed 2014 Nov 21

5. Pauliuk S, Wang T, Müller DB (2013) Steel all over the world: estimating in-use stock of iron for 200 countries. Resour Conserv Recycl 71:22-30

6. Wang T, Müller DB, Graedel TE (2007) Forging the anthropogenic iron cycle. Environ Sci Technol 41:5120-5129

7. Hatayama H, Daigo I, Matsuno Y, Adachi Y (2010) Outlook of the world steel cycle based on the stock and flow dynamics. Environ Sci Technol 44:6457-6463

8. Mills TC (1990) Time series techniques for economists. Cambridge University Press, Cambridge

9. Asteriou D, Hall SG (2011) ARIMA models and the Box-Jenkins methodology, applied econometrics. Palgrave MacMillan, New York

10. Box GEP, Gwilym MJ, Gregory CR (2008) Time series analysis: forecasting and control, 4th edn. Wiley, New Jersey

11. Kim Y (1994) Time series analysis. Freedom Academy, Seoul

12. Sohn I (2014) Future steel technology forum report 2013, Korea Steel Association

13. Haan A (2010) A defining moment? China's social policy response to the financial crisis. J Int Dev 22(6):758-771

14. Duan J-P, Zhanga Y-L, Yang X-M (2009) EAF steelmaking process with increasing hot metal charging ratio and improving slagging regime. Int J Miner Metall Mater 16(4):375-382

15. Madias J (2014) Chapter 1.5. Electric furnace steelmaking. In: McLean A, Guthrie R, Sridhar S (eds) Treatise on process metallurgy, vol 3A: industrial processes. Elsevier, Amsterdam, pp 271-297

16. Gielen D, Taylor P (2009) Indicators for industrial energy efficiency in India. Energy 34(8):962-969

17. Katz L (1953) A new status index derived from sociometric data analysis. Psychometrika 18:34-43 